\title{
BETEPHIAPHWIE HAYKn
}

\author{
УДК 636.5.064.6
}

\section{ИЗУЧЕНИЕ ВЛИЯНИЯ ДАФС-25 В ЛИПОСОМАЛЬНОЙ ФОРМЕ НА РОСТ И РАЗВИТИЕ ЦЫПЛЯТ}

\author{
Князева Юлия Владимировна \\ студентка ФГБОУ ВО Ижевская ГСХА, г. Ижевск \\ Михеева Екатерина Александровна \\ дочент, канд. вет. наук, \\ доиент кафедры инфекичионных болезней и патологической анатомии \\ ФГБОУ ВО Ижевская ГСХА, г. Ижевск \\ Шишкин Александр Валентинович \\ профессор доктор мед. наук, профессор кафедры анатомии и физиологии \\ ФГБОУ ВО Ижсевская ГСХА, г. Ижевск \\ Бабинцева Татьяна Викторовна \\ канд. вет. наук, ассистент кафедры инфекиионных болезней и патологической анатомии \\ ФГБОУ ВО Ижевская ГСХА, г. Ижевск \\ DOI: $\underline{10.31618 / E S U .2413-9335.2019 .5 .63 .181}$
}

АННОТАЦИЯ

Целью работы явилось изучение влияния перорального введения ДАФС-25 в липосомальной форме на рост и развитие цыплят. По результатам исследования получен равнозначный эффект влияния препарата на рост и развития при стандартной и меньших дозировках селена. У цыплят, получавших добавку, отмечались отличная поедаемость корма, высокая активность и своевременное половое созревание.

\section{ABSTRACT}

The aim of the work was to study the effect of oral introduction of DAFS-25 in liposomal form on the growth and development of chickens. According to the results of the study, the equivalent effect of the drug on growth and development at standard and lower dosages of selenium was obtained. In chickens, receiving the additive, there was an excellent feed palatability, high activity and timely puberty.

Ключевые слова: цыплята, ДАФС-25, селен, рост, развитие.

Keyword: chickens, DAFS-25, selenium, growth, development.

Территория Удмуртской Республики располагается в зоне с дефицитом некоторых микроэлементов, в частности селена, кобальта, йода, цинка и др. Применяемы на сегодняшний день препараты данных элементов не достаточно полно отвечают требованиям организма животных и не отличаются высокой биодоступностью $[2,3,4]$.

Для получения хорошей продукции в птицеводстве важным звеном является селен. Селен обладает высокой биохимической активностью и способствует интенсификации обмена веществ. Он влияет на процессы тканевого дыхания, регулирует скорость течения окислительно-восстановительных реакций, повышает иммунную реактивность организма. Его недостаток в рационах приводит к снижению роста и развития молодняка, снижению продуктивности и ухудшению воспроизводительных качеств животных, а также нарушению обмена веществ в организме $[1,5]$.

Селен применяется в практике животноводства в виде добавки ДАФС-25 (диацетофенонилселенид), которая обладает умеренной токсичностью, но малой биодоступностью и высокой стоимостью. Исходя из этого, изыскание форм селена с высокой биодоступностью, низкой токсичностью и ценовым коэффициентом, является актуальнам. Решить указанные проблемы можно путем повышения биодоступности за счет использования перорально вводимой в липосомальной форме ДАФС-25. При этом можно будет эксплуатировать физиологические и биохимические механизмы, аналогичные тем, которые используются организмом, например, в процессе всасывания липидов.

Цель: изучить влияние перорального введения ДАФС-25 в липосомальной форме на рост и развитие цыплят.

Задачи:

- определить суточные привесы при скармливании ДАФС-25 в различных концентрациях;

- оценить общее физиологическое состояние цыплят после перорального введения ДАФС-25 в липосомальной форме.

Материалы и методы

Исследования проводили на кафедре инфекционных болезней и патологической анатомии ФГБОУ ВО Ижевской ГСХА. Объектом исследования явились цыплята кросса Ломанн ЛСЛ в возрасте 2,5 месяца в количестве 12 голов, подобранных в группы с учетом веса. Откорм осуществляли 1 месяц по стандартному рациону с учетом возраста.

Разведение ДАФС-25 в липосомальной форме готовили из расчета 1,$6 ; 0,32$ и 0,16 мг/кг корма (соответственно 1,2 и 3 опытные группы). Контрольная группа добавку не получала. После скармливания корма с ДАФС-25, цыплята в течение суток дополнительно получали корм не содержащего добавку. В процессе откорма определяли суточный 
прирост на 7, 14, 21, 28 и 35 сутки. Оценивали поедаемость корма, внешний вид цыплят и их активность.

\section{Результаты исследований}

Данные по изменению живой массы цыплят опытных и контрольной групп отражены в таблице 1. Сравнительный анализ суточных привесов цыплят опытных групп с контролем по окончании опыта показал, что наилучший прирост имели цыплята 1 опытной группы (с концентрацией добавки 1,6 мг/ кг корма). Так, к 35 сут. исследования в данной опытной группе среднесуточный прирост составил $1060,0 \pm 69,3$, что на 80 г больше по сравнению с контролем.

Среднесуточный прирост цыплят, г

\begin{tabular}{|c|c|c|c|c|c|}
\hline \multirow{2}{*}{$\begin{array}{c}\text { Группа } \\
(\mathrm{n}=3)\end{array}$} & \multicolumn{5}{|c|}{ Время исследования, сут. } \\
\cline { 2 - 6 } & 7 & 14 & 21 & 28 & 35 \\
\hline Контроль & $902,5 \pm 60,2$ & $917,5 \pm 59,1$ & $940,0 \pm 63,3$ & $957,5 \pm 69,0$ & $980,0 \pm 73,5$ \\
\hline 1 опытная & $903,3 \pm 92,9$ & $930,0 \pm 88,9$ & $976,7 \pm 80,8$ & $1016,6 \pm 75,7$ & $1060,0 \pm 69,3$ \\
\hline 2 опытная & $900,0 \pm 43,6$ & $920,0 \pm 34,6$ & $956,7 \pm 40,4$ & $990,0 \pm 26,5$ & $1030,0 \pm 43,6$ \\
\hline 3 опытная & $906,7 \pm 25,2$ & $940,0 \pm 45,8$ & $970,0 \pm 62,5$ & $1023,3 \pm 45,1$ & $1050,0 \pm 50,0$ \\
\hline
\end{tabular}

Рассматривая разницу суточных приростов, можно сделать вывод, что добавка с минимальной концентрацией препарата (0,16 мг/кг корма) показала не менее хорошие результаты. Такая тенденция просматривалась во все периоды исследования (рис. 1)

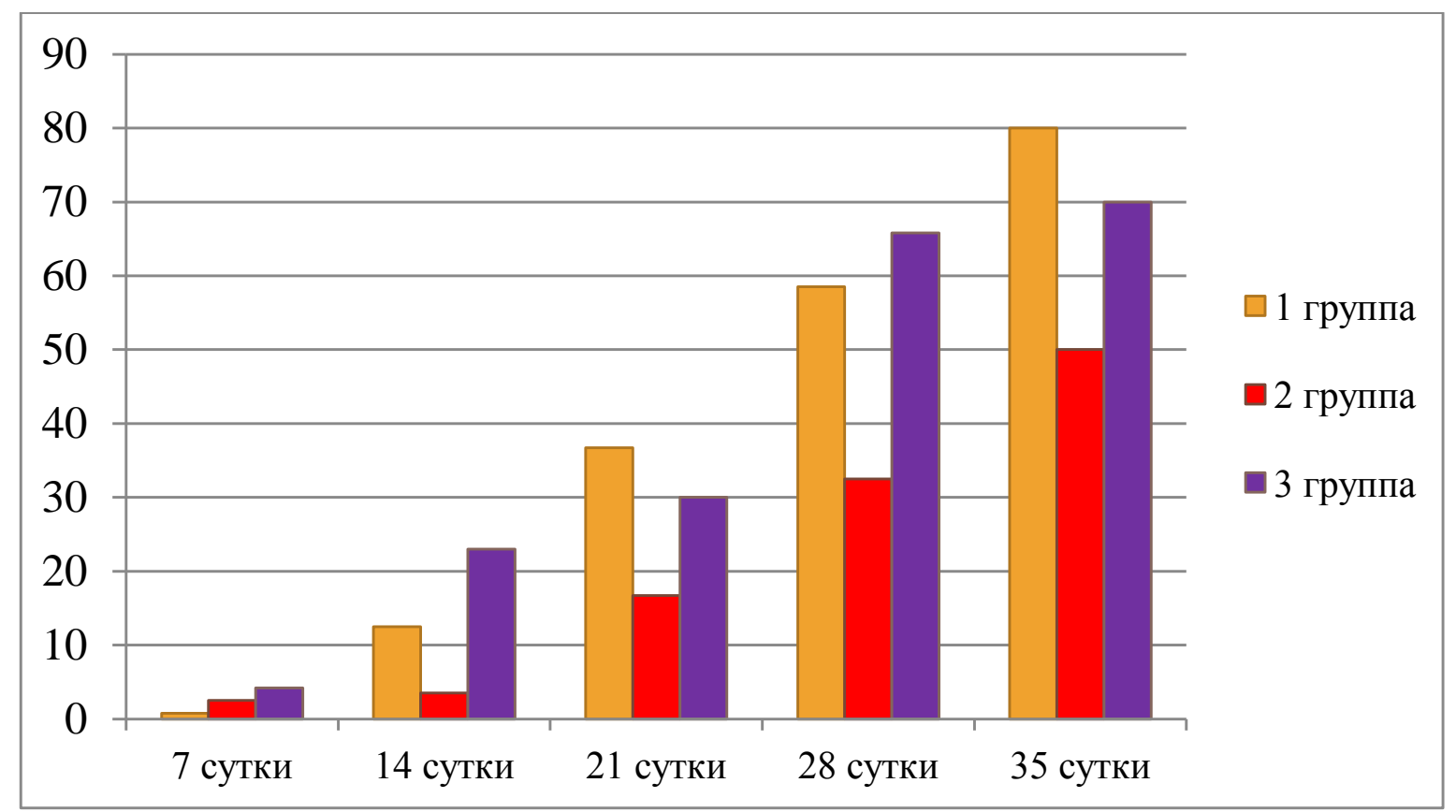

Рисунок 1. Сравнительная характеристика суточных приростов изыплят опытных групп, 2

Оценивая активность поведения и поедаемость корма, необходимо отметить, что достоверной разницы в поведении, поедаемости корма и активности цыплят всех опытных групп не было выявлено. На протяжении всего периода исследования, как петушки, так и курочки имели хорошую оперяе- мость, чистые кожные покровы, роговые образования желтоватого цвета. Внешние признаки свидетельствовали о своевременном половом созревании (рис. 2, 3). У птиц контрольной группы роговые образования более светлого цвета, гребешок и бородка несколько бледнее, поедаемость корма не отличалась от кур опытных групп. 

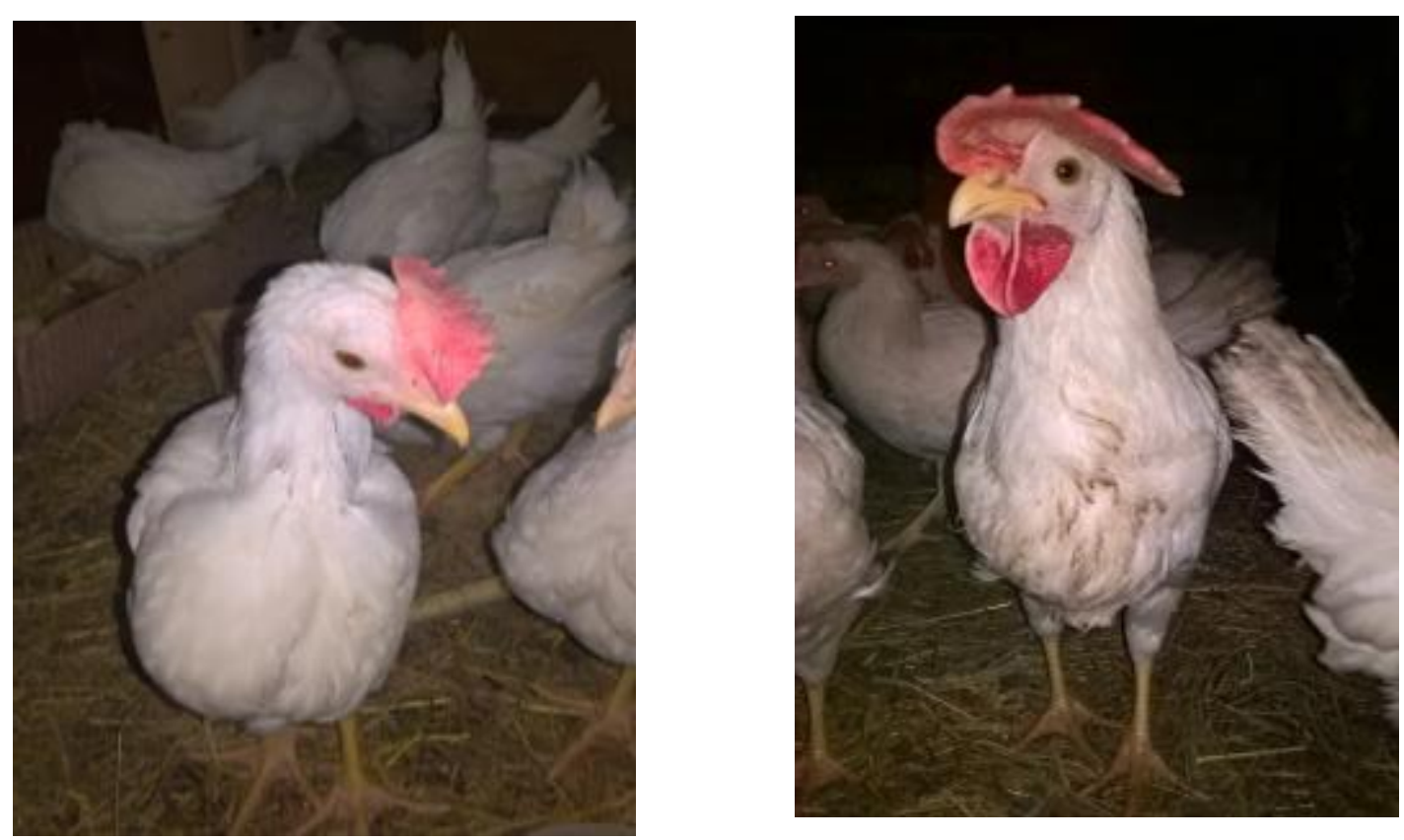

$A$

Рисунок 2. Показатели развития петушков опытных групп до (А) и после (Б) применения добавки

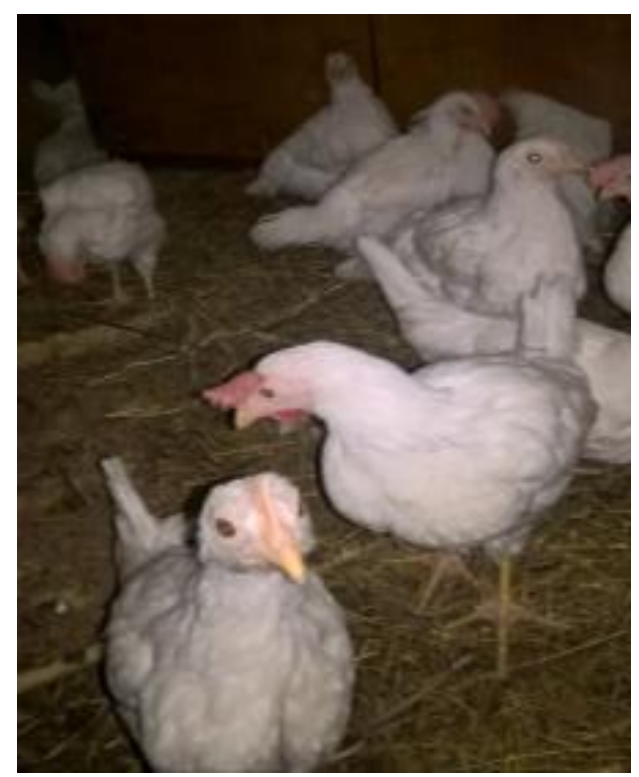

$A$

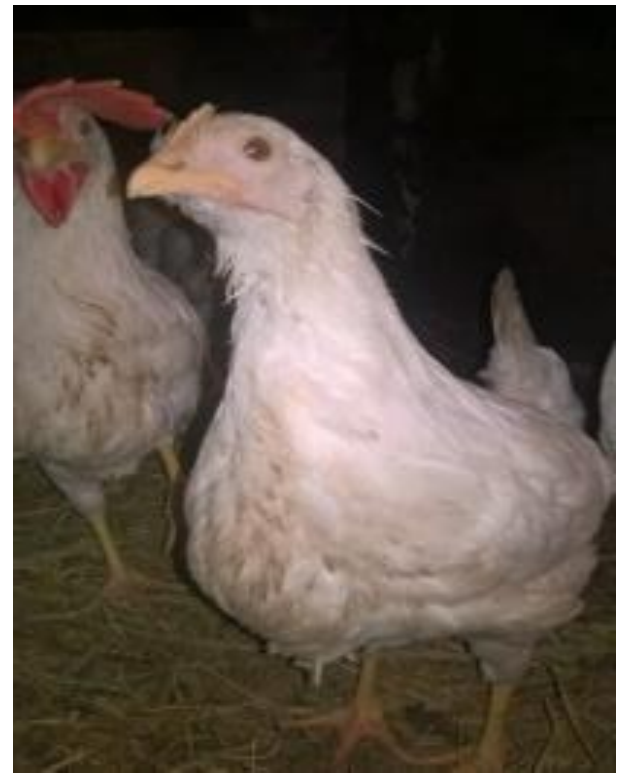

Б

Рисунок 3. Показатели развития курочек

опьытных групп до (А) и после (Б) применения добавки

В связи с тем, что были получены хорошие результаты при снижении количества ДАФС-25 в 10 раз (группа 3), даже с учетом стоимости реагентов, необходимых для образования липосом, можно утверждать, что расходы на изготовление кормовой добавки будут в $5-7$ раз меньше.

\section{Выводы:}

- имея небольшую разницу в приросте между группами, нет необходимости добавлять максимальную концентрацию препарата, если при минимальной концентрации можно получить такой же эффект; 
- у цыплят, получавших добавку, отмечались отличная поедаемость корма, высокая активность и своевременное половое созревание.

Список литературы:

1. Алексеева С.А. Общие и местные факторы иммунитета кур-несушек при использовании селеноорганических препаратов сел-плекс и ДАФС-25 / С.А. Алексеева, Рубцов В.В. // Ветеринарная патология. - 2006. - № 2 (17). - С. 123-126.

2. Берестов Д.С. Гематология / Д.С. Берестов, Ю.Г. Васильев. Ижевск, 2018. - 120 с.

3. Михеева Е.А. Анализ показателей сыво- ротки крови у крупного рогатого скота в племенных хозяйствах удмуртской республики / Е.А. Михеева, Л.Ф. Хамитова, Ю.Г. Васильев // Вестник Ижевской государственной сельскохозяйственной академии. - 2011. - № 3 (28). - С. 20-23.

4. Перевозчиков Л.А. Роль нарушений обмена веществ в возникновении патологии дистального отдела конечностей крупного рогатого скота / Л.А. Перевозчиков, Е.А. Михеева // Вестник Ижевской государственной сельскохозяйственной академии. - 2013. - № 2 (35). - С. 49-51.

5. Чепрасова О. Влияние препарата ДАФС-25 на продуктивность бройлеров / О. Чепрасова и др. // Птицеводство. - 2007. - № 10. - С. 23.

\title{
ПАТОЛОГИИ СЕРДЦА У СОБАК МЕЛКИХ ПОРОД ДИАГНОСТИКА НА ПРИМЕРЕ МИКСОМАТОЗНОЙ ДЕГЕНЕРАЦИИ АТРИОВЕНТРИКУЛЯРНЫХ КЛАПАНОВ СЕРДЦА
}

\author{
Юдина Екатерина Анатольевна \\ Аспирант, кафедра «Общая патология», \\ ФГБОУ ВО Московская ГАВМиБ - МВА им. К.И.Скрябина, г. Москва \\ Рыбкова Ольга Олеговна \\ Аспирант, кафедра «Общая патология», \\ ФГБОУ ВО Московская ГАВМиБ - МВА им. К.И.Скрябина, г. Москва
}

\begin{abstract}
АННОТАЦИЯ
Миксоматозная дегенерация атриовентрикулярных клапанов (МДКС) является наиболее часто встречающимся приобретенным заболеванием сердца генетической этиологии у собак мелких пород. Для диагностики болезни необходимо проводить общее клиническое обследование, оценивать лабораторные показатели, а также данные эхокардиографии, последняя является эталонным методом, позволяющим оценить функциональные и морфологические изменения органа при данной патологии.
\end{abstract}

\section{ABSTRACT}

Myxomatous degeneration of the atrioventricular valves is the most common acquired heart disease with genetic etiology in dogs of small breeds. For diagnose the disease, it is necessary to conduct a physical examination, assessment of laboratory parameters, and also echocardiography, which is a reference method for assessing functional and morphological changes of the organ in this pathology.

Ключевые слова: миксоматозная дегенерация атриовентрикулярных клапанов сердца, эхокардиография, чихуахуа.

Keywords: myxomatous degeneration of atrioventricular valves of the heart, echocardiography, chihuahua

\section{АКТУАЛЬНОСТЬ}

В настоящее время продолжается рост разведения собак мелких пород. По исследованию Российской кинологической ассоциации, проведенному в 2016 году, самыми популярными в Москве стали представители декоративных пород. На третьем месте в рейтинге - собаки породы чихуахуа [2, с.1].

В связи с жесткой селекцией и инбридингом, а также некоторыми особенностями строения, декоративные породы собак имеют предрасположенность ко многим патологиям. Ярким примером их является брахицефалический синдром, коллапс трахеи и др. Щенки часто рождаются с гидроцефалией, что впоследствии приводит к поражению ЦНС и нервным расстройствам.

Патологии сердца различной этиологии также не являются редкостью у декоративных собак.

Существует несколько классификаций заболеваний сердца по этиологическому принципу. В большинстве публикаций выделяют две большие группы кардиопатологий: врожденные и приобретенные. Врожденные пороки сердца формируются в период внутриутробного развития в результате нарушения эмбрионального морфогенеза, и могут быть обусловлены как наследственными (генные, хромосомные, геномные, зиготические мутации), так и средовыми факторами, влияющими на зародыш (экзогенные воздействия на организм матери, а также внутренние заболевания материнского организма) [3, с. 122].

К приобретенным болезням сердца относят патологии, возникающие под действием эндо- и экзогенных патологических факторов после рождения в течение жизни животного. Возникают болезни под действием биологических, химических, физических, механических факторов.

К приобретенным заболеваниям сердца относятся и кардиомиопатии - первичные поражения миокарда, сопровождающиеся нарушением его структуры и функций и не являющееся следствием других заболеваний, прежде всего венечных артерий, клапанного аппарата, перикарда, артериальной гипертензии. Это поражение обычно медленно прогрессирует [1, с. 301]. Кардиомиопатиям собак посвящено много научных трудов. Для многих 